\title{
Gestation in a Mare with Facial Deviation (Wry Nose)
}

\author{
Gestação em uma égua com desvio facial (Wry Nose) \\ Mariana Andrade Mousquer', Vitória Müller', Fernanda Maria Pazinato ${ }^{2}$, Bruna dos Santos Suñe Moraes', \\ Leandro Américo Rafael', Bruna da Rosa Curcio' \& Carlos Eduardo Wayne Nogueira'
}

\begin{abstract}
Background: Wry nose is a congenital deformity that causes respiratory obstruction and decreased oxygenation rate. Gestation in a wry nose mare may be considered a risk to the neonate since it depends on the maternal environment for development. Compromised oxygenation during pregnancy can lead to fetal distress and cause consequences on fetal development. However, depending on the degree of the impairment, the fetus may still be able to adapt. The aim of the present study was to report the gestation in a mare with facial deviation until term and to assess blood gases in the mare and neonate, and to evaluate the histomorphometry of the placenta.

Case: A Criollo breed mare presenting facial deviation (Wry Nose) was donated to Equine Medicine Research Group (ClinEq) of the Federal University of Pelotas (UFPel) due to the presence of the physical deformity. When the mare was five years old, it was inseminated and had a pregnancy confirmed. At the fifth month of gestation, evaluation of fetal aorta diameter, fetal orbital diameter and combined thickness of the uterus and placenta (CTUP) started to be performed monthly to assess gestation health. The assessment of the fetal orbit and aorta diameter revealed a linear increase of both variables with the progress of gestation indicating a normal fetal development. CTUP remained in the normal reference range, presenting no alterations during the gestational length. The mare foaled at 324 days of gestation a coat showing no congenital deformities. The foaling was monitored until the complete passage of fetal membranes. A complete clinical and hematological evaluation of the foal was carried out after birth. The foal showed normal adaptive behavior, clinical and hematological parameters during the first hours of life, although presenting physical signs of immaturity. Venous blood samples were collected from the mare at 315 days of gestation, immediately after foaling and $24 \mathrm{~h}$ post-partum for lactate and blood gas analysis. Mild changes were observed in the mare's blood gas analysis at foaling that were compensated within $24 \mathrm{~h}$ post-partum. Venous blood samples were collected from the umbilical cord and from the foal after birth, at 12 and $24 \mathrm{~h}$ post-partum to measure blood gases and lactate. The newborn foal presented respiratory acidosis immediately after birth, which was metabolically compensated at $24 \mathrm{~h}$ post-partum. Both mare's and foal's lactate evaluation were within the normal reference ranges. After expulsion of the placenta, samples from the gravid horn, uterine body and non-gravid horn were collected for histological and histomorphometric evaluation. In the histological evaluation, avillous areas were detected in the gravid horn and uterine body and mild hypoplasia was found in the uterine body. Placental histomorphometry revealed larger total microcotiledonary and capillary areas on the non-gravid horn when compared to the remaining areas of the placenta (gravid horn and uterine body). No abnormalities on the placental vasculature were detected. Discussion: To date, there are no reports of a pregnancy in a mare with facial deviation in the literature. This report showed that the wry nose mare gave birth to a viable foal showing no congenital abnormalities, which suggests that wry nose animals can be bred normally. The mare presented a healthy pregnancy, with mild changes in the blood gas analysis at foaling that were compensated at $24 \mathrm{~h}$ postpartum. Similarly, despite the foal showed physical signs of immaturity and respiratory acidosis at birth, these changes were compensated in the later assessments. Furthermore, no abnormalities on the placental vasculature were detected.
\end{abstract}

Keywords: blood gas analysis, neonate, histomorphometry, congenital deformity, facial deviation.

Descritores: hemogasometria, neonate, histomorfometria, deformidade congenital, desvio facial.

DOI: $10.22456 / 1679-9216.95448$

Received: 14 May 2019

Accepted: 2 August 2019

Published: 19 September 2019

${ }^{1}$ Departamento de Clínicas Veterinária, Faculdade de Medicina Veterinária, Universidade Federal de Pelotas (UFPel), Capão do Leão, RS, Brazil. ${ }^{2}$ Departamento de Clínicas Veterinárias, Universidade do Oeste de Santa Catarina (Unoesc), Xanxerê, SC, Brazil. CORRESPONDENCE: M.A. Mousquer [mmousquer.vet@gmail.com] \& C.E.W. Nogueira [cewn@terra.com.br]. Campus Universitário - Hospital de Clínicas Veterinárias, UFPel. CEP 96010-900 Capão do Leão, RS, Brazil. 


\section{INTRODUCTION}

Facial deviation, also known as wry nose (campylorrhinus lateralis), is a congenital deformity that affects the bones of maxilla, nasal bones, vomer and nasal septum causing a rostral deviation for either left or right side $[10,20]$. The cause of this defect is still unknown. It is suggested that its development could be related to little uterine expansion, which would occur mainly in primiparous mares. However, there are reports in foals born from multiparous mares [26,30].

Wry nose can lead to respiratory obstruction and decreased oxygenation rate [10]. For this reason, pregnancy in a wry nose mare could be considered at risk since it may indicate oxygen deprivation to the fetus. Consequences of compromised oxygenation during pregnancy can range from intrauterine growth restriction to abortion [9]. Depending on the extent and duration of the impairment of oxygenation, the fetus may still be able to adapt using several responses to hypoxia [23]. Additionally, it has been described in other species that the placenta can develop compensatory mechanisms for chronic hypoxia as a rise in the number of capillaries [7].

To the authors' knowledge, there are no reports of wry nose mares carrying gestations to term. Owners are usually encouraged to do not bred these animals. Moreover, the existence of a heritability factor for this deformity is still unknown. The overall aim of the present study is to report a pregnancy at term in a mare with facial deviation. Specific aims are (i) to evaluate blood gases parameters in venous blood and lactate profile of the mare and the respective foal from birth to $24 \mathrm{~h}$ postpartum and (ii) to assess histomorphometric features of the placenta.

\section{CASE}

\section{Mare's history}

A 3-year-old Criollo mare was donated to the Equine Medicine Research Group (ClinEq) of the Federal University of Pelotas (UFPel) due to the presence of a congenital facial deviation. At the time, the owner reported that the donated animal was the first generation of a mare that did not present any phenotypic or clinical alteration, and, in the following years, the same mare had given birth to healthy foals. The mare was housed at the Palma Farm of the Federal University of Pelotas. All procedures carried out in this study were approved by the Ethical Committee on Animal Experimentation of the Federal University of Pelotas, under the number $\# 8245$.

At the time of arrival, the mare had all the vital parameters within the reference values for the species [28], presenting only a respiratory noise at rest. A radiographic exam of the face was performed using a digital x-ray machine (Slate $3+)^{1}$ and the deviation of the nasal, maxillary and incisor bones towards right was observed (Figure 1). A biometric profile was performed according to the parameters defined by the Criollo Horse Breeders Association [1]. The mare presented height of $1.35 \mathrm{~m}$, body weight of $300 \mathrm{~kg}$, circumference of the cannon bone of $15 \mathrm{~cm}$ and thoracic perimeter of $1.56 \mathrm{~m}$. Because of the presence of the facial deviation, together with these measures that did not meet the minimum requirement for Criollo breed females, it was not possible to obtain the genealogical record.

\section{Gestation and parturition}

When the mare had 5-years old, a gynecological exam was performed, and the mare was inseminated. Twelve days after ovulation, pregnancy was confirmed, and the mare was kept under paddock rotation, with water ad libitum during the gestation period. Body condition score was maintained between 6 and 7 throughout pregnancy, according to the score system described by Henneke [13]. Starting at the fifth month of gestation, transrectal and transabdominal ultrasonography were performed monthly to measure fetal aorta diameter, orbital diameter and the combined thickness of the uterus and placenta (CTUP) [Table 1]. The measurement of the CTUP was performed as previously described [22]. The fetal orbit was measured according to the technique described by Hartwig et al. [12], while fetal aorta measurement was performed by transabdominal ultrasonography with convex transducer $(3.5 \mathrm{MHz})$ [5].

When the mare completed 315 days of gestation, it was kept in an observational paddock. When imminent signs of parturition were observed, the mare was closely monitored until the passage of fetal membranes was completed. The foaling was uneventful. The mare foaled a colt at 324 days of gestation with birth weight of $33 \mathrm{~kg}$, height of $82 \mathrm{~cm}$ and showing some physical signs of immaturity (domed head and silky hair coat). The foal presented normal postural reflexes except for a delay in the suction reflex, which occurred at $22 \mathrm{~min}$ after birth [28]. The foal did not 
present any congenital deformity, underwent a full clinical exam and complete blood count after parturition. Hematologic and clinical parameters were within the reference values described by Koterba [14] for newborn foals.

\section{Blood samples}

Venous blood samples were obtained from the mare in the eleventh month of gestation, immediately after foaling $(0 \mathrm{~h})$ and $24 \mathrm{~h}$ postpartum through venipuncture of the external jugular vein for blood gas analysis (Table 2). Blood lactate assessment of the mare was performed at $0 \mathrm{~h}$ and $24 \mathrm{~h}$ postpartum (Table 2). A blood sample was collected from the umbilical vein immediately after the foal expulsion. Blood samples from the external jugular vein of the foal were collected after parturition $(0 \mathrm{~h})$ and then repeated $12 \mathrm{~h}$ and $24 \mathrm{~h}$ postpartum (Table 3 ). Blood samples of the foal were used to determine lactate concentration and blood gases. Hemogasometry was performed using a portable I-STAT analyzer ${ }^{2}$ with CG8+ cartridge $^{2}$, while lactate concentrations were determined by an Accutrend Plus multi-analyzer portable device ${ }^{3}$.

\section{Placenta evaluation}

The placenta was expelled in the first hour postpartum. After expulsion, it was weighed $(3.3 \mathrm{~kg})$ and extended onto a flat surface for gross evaluation of both chorionic and allantoic surfaces. A small rupture in the final portion of the gravid horn was observed, but it was attributed to the manipulation. The chorionic surface had red velvet-like appearance and, small avillous areas were identified on the body and gravid horn. No secretion or thickened areas were observed. After gross evaluation, samples of the placenta were collected from the following regions: cervical star, uterine body, gravid horn, non-gravid horn, bifurcation, amnion and umbilical cord. Samples were submitted for histological evaluation according to the method described elsewhere $[19,25]$. In the histological evaluation, mild microcotiledonary hypoplasia in the body region and avillous areas in the body and gravid-horn were identified (Figure 2).

For histomorphometric features, digital images of samples were obtained using Olympus BX51 microscope $e^{4}$, and evaluated using a public domain software (NIH ImageJ 1.48r, available at: http://rsb. info.nih.gov/i1/ $)^{5}$. The images were obtained in objective of $40 \mathrm{x}$ (scale of $50 \mu \mathrm{m}$ or $100 \mu \mathrm{m}$ ) to evaluate total microcotiledonary area, capillary area, total vessel diameter and vessel lumen diameter. The technique used to evaluate the placenta histomorphometry was previously described [19]. The total field area related to the images used was $73.254 \mu \mathrm{m}^{2}$. Descriptive statistics was performed from placental areas (uterine body, gravid horn and non-gravid horn) and are described as mean \pm SE (Table 4). Differences of the histomorphometric features between placental areas evaluated were performed by LSD All- Pairwise comparisons. The histomorphometric evaluation revealed a larger total microcotiledonary and capillary area in the nongravid horn compared to uterine body and gravid horn. No differences or alterations were identified in the placental vasculature [19] (Figure 3).

\section{DISCUSSION}

In the present study, we demonstrated that a wry nose mare gave birth to a viable foal. This suggests that mares presenting this deformity can be breed normally, since the foal did not present any congenital abnormality and the mare's condition showed no interference in the foal's survival. The assessment of the fetal orbit and aorta diameter revealed a linear increase of both variables with the progress of gestation, suggesting a normal development of the foal, which is in agreement with previous studies $[4,12]$. According to Bucca [4], fetal aorta diameter is the parameter that correlates most closely with fetal size and birth weight. This technique was also used to determine the presence of fetal stress and allow early intervention [21]. The values obtained from the CTUP evaluation were within the normal reference range for each month of gestation [22].

The mare's blood gas assessment at the eleventh month of gestation did not show any abnormality. At the time of foaling, the mare presented a mild increase in $\mathrm{PCO}^{2}$, despite showing normal blood $\mathrm{pH}$, and a decrease in oxygen saturation according to the parameters for the species $[8,27]$. The alterations found at parturition might be related to the moment itself, although, to the authors' knowledge, there is no data that can affirm this. On the other hand, the facial deformity could have exacerbated the respiratory effort causing the alterations observed. All changes in the blood gas analysis were compensated at $24 \mathrm{~h}$ postpartum. Lactate values remained in the reference range at both time points observed [6,31]. 


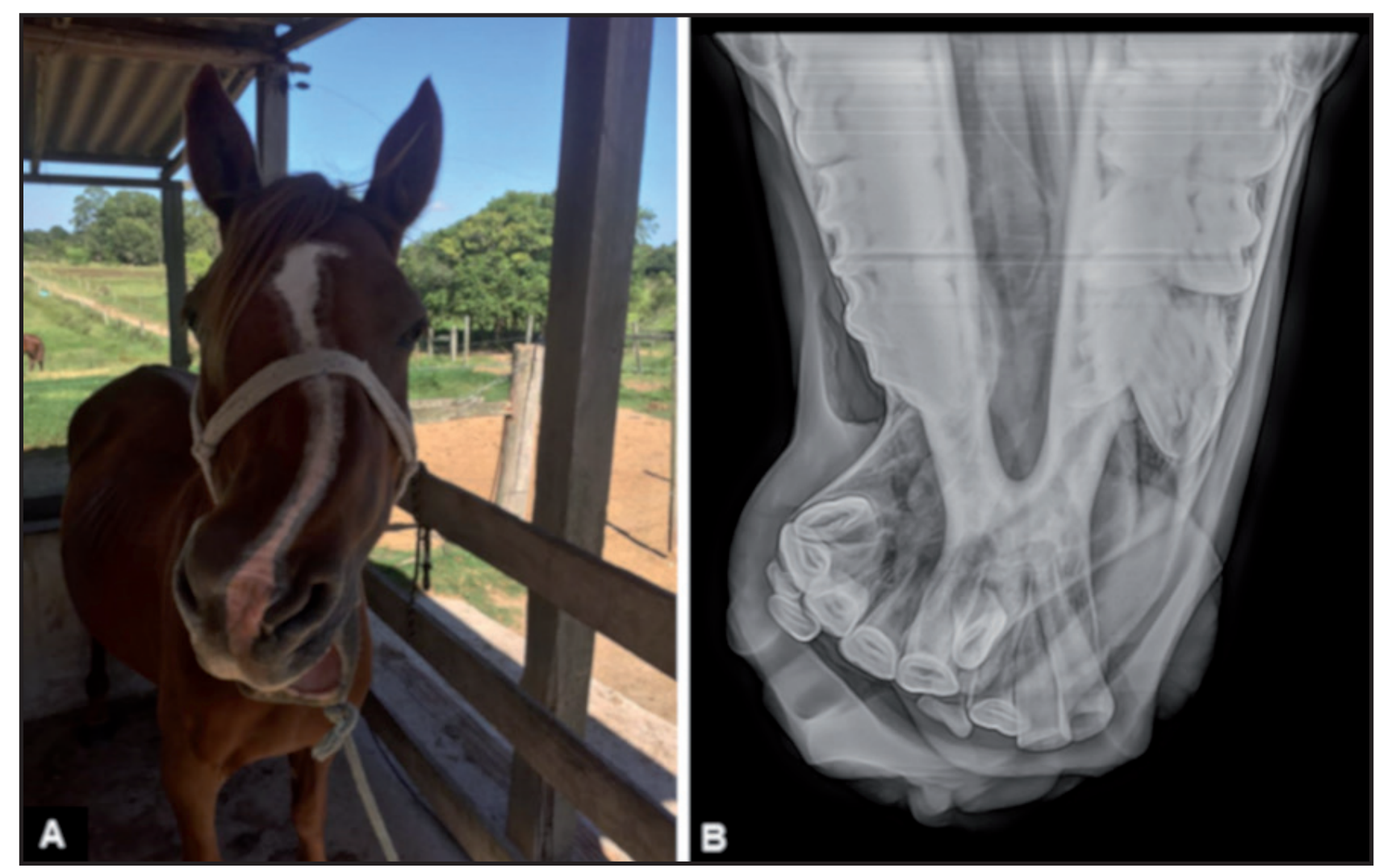

Figure 1. A- Mare presenting facial deviation towards right. B- Rostroventral radiography showing the deviation of nasal, maxillary and incisor bones of the head.

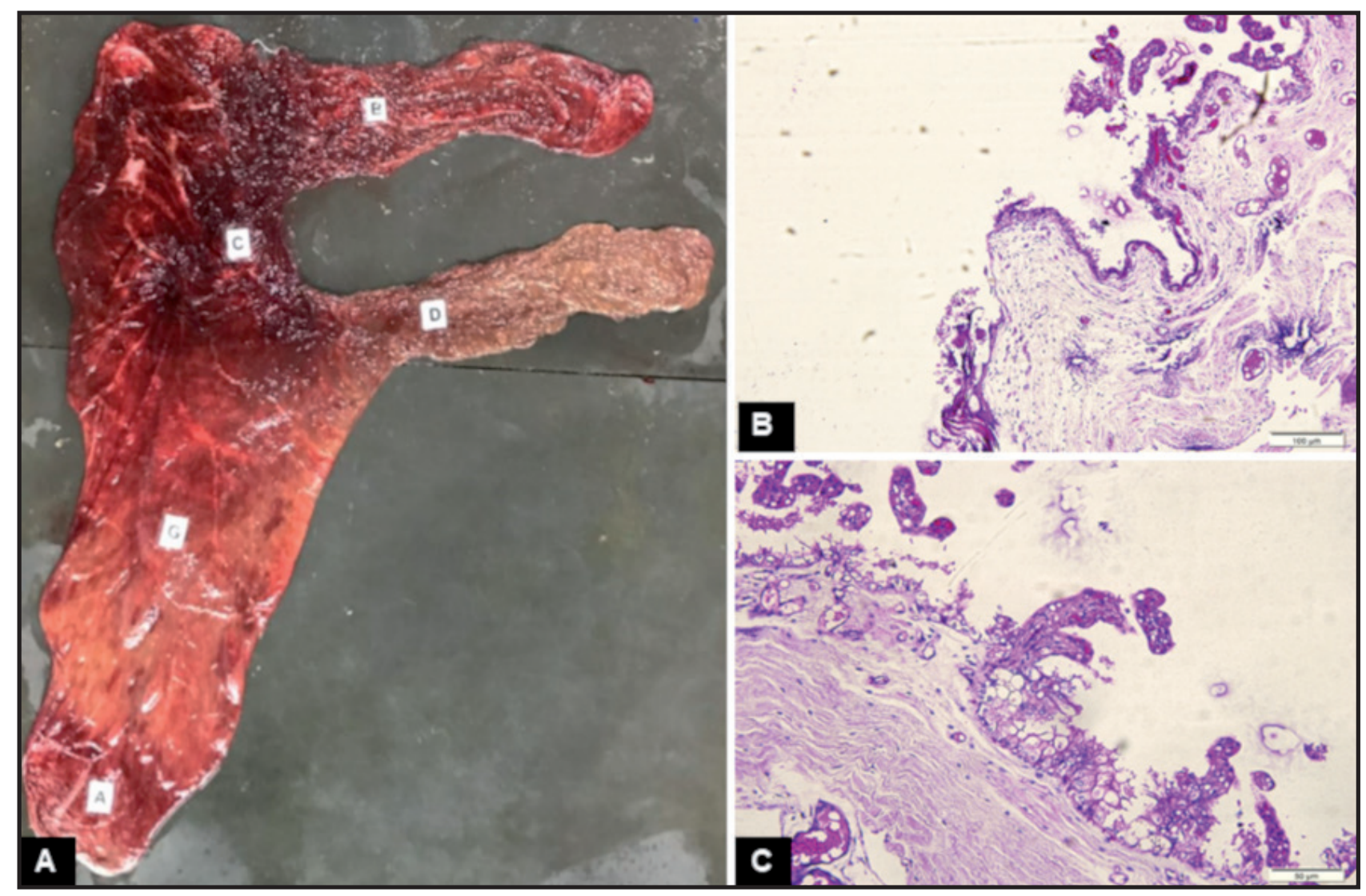

Figure 2. A- Macroscopic appearance of the placenta, regions identified by letters [A- cervical star, G- Uterine body, C- Bifurcation, B- Gravid horn and D- Non-gravid horn]. B- \& C- Uterine body region of placenta with microcotyledonary hypoplasia, characterized by short villi, narrowed base and regions absent of microcotyledones [HE; Obj.40x]. 


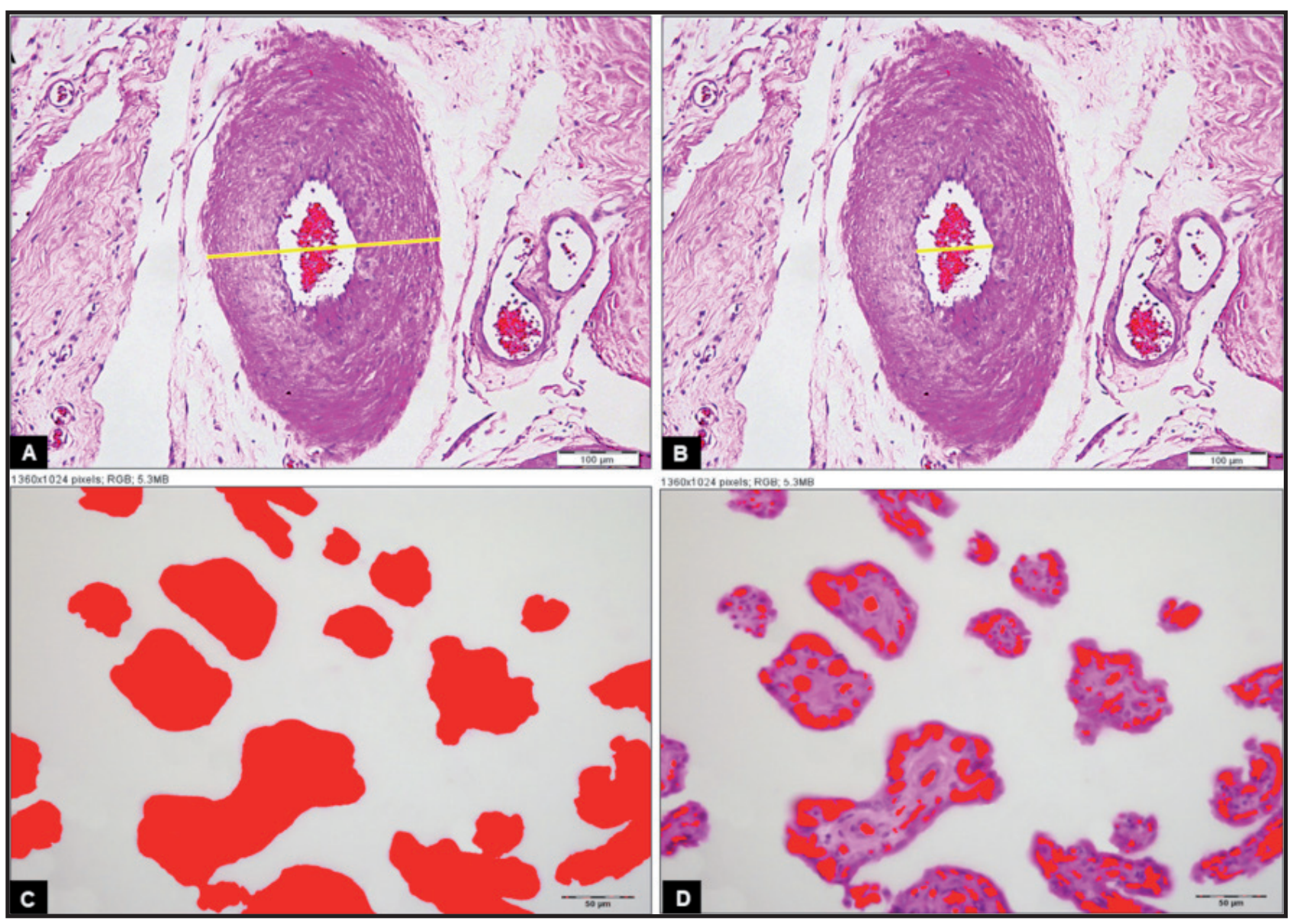

Figure 3. Histomorphometry technique for evaluation of the placenta. A- Measure of total vascular diameter of a vessel from the gravid horn [Scale bar= $100 \mu \mathrm{m}$ ]. B- Measure of the lumen of the vessel in the gravid horn [Scale bar= $100 \mu \mathrm{m}$ ]. C- Total microcotiledonary area from gravid horn, areas selected by Plug in using "ColorThreshold" method (total field area of $73.254 \mu \mathrm{m}^{2}$ ) [Scale bar= $50 \mu \mathrm{m}$ ]. D- Selection of capillary area in the microcotyledones by the plug in "ColorThreshold" [Scale bar $=50 \mu \mathrm{m}]$.

At birth, the blood gas analysis of the foal revealed respiratory acidosis. Similar results were observed in preterm foals $[11,14]$. Premature and dysmature foals are susceptible to hypoventilation, which in this case is identified by hypercapnia and mild hypoxemia $[14,15]$. The foal showed a reduction in the $\mathrm{PCO}^{2}$ values at $12 \mathrm{~h}$ and $24 \mathrm{~h}$, with $\mathrm{pH}$ normalization, indicating a compensatory adaptation of the respiratory acidosis. This is confirmed by an increase in BEecf and $\mathrm{HCO} 3$ - values from birth to $24 \mathrm{~h}$ [14]. In regard to the umbilical cord blood gas analysis, a decrease in the $\mathrm{PO}^{2}$ was observed. Umbilical venous $\mathrm{PO}^{2}$ should be around 50-54 mmHg, which also indicates hypoxemia [32]. No abnormalities were found in the foal's blood lactate at all time points observed [6,31].

The presence of signs of immaturity, the low birth weight for the breed [18] and the findings of the blood gas analysis at birth suggest that the foal could have suffered some degree of stress while in uterus, which may be related to the respiratory alteration of the mare. This can also be inferred considering the gestation length of the mare of this study, as it is known that fetuses that experience some type of stress tend to mature earlier, signaling the birth process at a shorter gestational age [17]. Such foals may show some clinical signs of pulmonary immaturity that can range from nostril flare to more complicated impairment of breath, or mild pulmonary hypertension derived from a persistent fetal circulation [17]. In addition, it was the first gestation of the wry nose mare, which could have contributed to the factors observed in the foal. It is suggested that the anatomical and physiological immaturity of the reproductive tract could interfere in the gestational length, being longer than what occurs in multiparous mares [24].

The histomorphometric assessment of the placenta revealed a larger total area of microcotyledons and capillaries in the non-gravid horn than in comparison to gravid horn and uterine body, inferring the presence of a higher density of microcotyledons in that region $[3,16]$. This finding could indicate a compensatory response to allow metabolic exchange 
Table 1. Assessment of CTUP, fetal orbit diameter and fetal aorta diameter throughout pregnancy.

\begin{tabular}{cccc}
\hline Month of gestation & CTUP $(\mathrm{mm})$ & Fetal orbit $(\mathrm{mm})$ & Fetal aorta $(\mathrm{mm})$ \\
\hline 5 & 3.04 & 22.13 & 9.3 \\
6 & 3.61 & 24.25 & 10.4 \\
7 & 2.8 & 26.67 & 11 \\
8 & 4.32 & 26.79 & 11.6 \\
9 & 5.74 & 27.53 & 13.3 \\
10 & 6.16 & $*$ & 14.6 \\
11 & 6.14 & 31.42 & 17.6 \\
\hline
\end{tabular}

*Fetal orbit was not performed at the tenth month of gestation.

Table 2. Blood gas analysis of the wry nose mare at the eleventh month of gestation, after foaling and $24 \mathrm{~h}$ post-partum.

\begin{tabular}{cccc}
\hline Blood gas analysis & $11^{\text {th }}$ month of gestation & foaling $(0 \mathrm{~h})$ & $24 \mathrm{~h}$ post-partum \\
\hline $\mathrm{pH}$ & 7.391 & 7.343 & 7.406 \\
$\mathrm{SvO}_{2}(\%)$ & 71 & 36 & 64 \\
$\mathrm{PvCO}_{2}(\mathrm{mmHg})$ & 39.8 & 54.9 & 46.2 \\
$\mathrm{PvO}_{2}(\mathrm{mmHg})$ & 37 & 23 & 34 \\
$\mathrm{BEecf}^{(\mathrm{mmol} / \mathrm{L})}$ & -1 & 4 & 4 \\
$\mathrm{HCO}_{3}(\mathrm{mmol} / \mathrm{L})$ & 24.1 & 29.8 & 29 \\
Lactate $(\mathrm{mmol} / \mathrm{L})$ & $*$ & 1.9 & 0.8 \\
\hline
\end{tabular}

*Blood lactate was not assessed at the eleventh month of gestation.

Table 3. Blood gas analysis of the umbilical vessel and of the foal delivered by the wry nose mare after foaling $(0 \mathrm{~h}), 12 \mathrm{~h} \mathrm{and} 24 \mathrm{~h}$ post-partum.

\begin{tabular}{ccccc}
\hline Blood gas analysis & Umbilical cord blood $(0 \mathrm{~h})$ & Foal blood $(0 \mathrm{~h})$ & Foal blood $(12 \mathrm{~h})$ & Foal blood $(24 \mathrm{~h})$ \\
\hline $\mathrm{pH}$ & 7.442 & 7.299 & 7.406 & 7.389 \\
$\mathrm{SvO}_{2}(\%)$ & 75 & 48 & 66 & 61 \\
$\mathrm{PvCO}_{2}(\mathrm{mmHg})$ & 44.6 & 65 & 52.1 & 48.5 \\
$\mathrm{PvO}_{2}(\mathrm{mmHg})$ & 39 & 30 & 35 & 32 \\
$\mathrm{BEecf}^{(\mathrm{mmol} / \mathrm{L})}$ & 6 & 5 & 8 & 4 \\
$\mathrm{HCO}_{3}(\mathrm{mmol} / \mathrm{L})$ & 30.5 & 31.9 & 32.7 & 29.3 \\
Lactate $(\mathrm{mmol} / \mathrm{L})$ & $*$ & 3.2 & 1.9 & 2.1 \\
\hline
\end{tabular}

*Blood lactate of the umbilical vessel was not assessed.

Table 4. Histomorphometric evaluation of the placenta (gravid horn, non-gravid horn and uterine body) of the wry nose mare.

\begin{tabular}{cccc}
\hline Histomorphometric features & Gravid horn & Non-gravid horn & Uterine body \\
\hline Total microcotiledonary area $\left(\mu \mathrm{m}^{2}\right)$ & $17394 \pm 458.48^{\mathrm{b}}$ & $20036 \pm 462.76^{\mathrm{a}}$ & $14466 \pm 582.05^{\mathrm{c}}$ \\
Total capillary area $\left(\mu \mathrm{m}^{2}\right)$ & $6129.8 \pm 301.69^{\mathrm{b}}$ & $9791.6 \pm 433.25^{\mathrm{a}}$ & $5529.7 \pm 357.69^{\mathrm{b}}$ \\
Vessel lumen diameter $(\mu \mathrm{m})$ & $51.96 \pm 6.49$ & $56.00 \pm 14.36$ & $41.49 \pm 8.19$ \\
Total vascular diameter $(\mu \mathrm{m})$ & $151.80 \pm 16.04$ & $177.69 \pm 25.24$ & $145.71 \pm 15.36$ \\
\hline
\end{tabular}

Different letters indicate statistical difference, $P \leq 0.05$. 
when lesions or avillous areas are present in other regions of the placenta $[3,16]$. On the other hand, the birth of a small foal from young mares can be attributed to a decrease in fetal nourishment, small intrauterine space and consequently to a lower placental total area which is usually found in primiparous mares [2]. The presence of avillous areas as well as microcotyledonary hypoplasia, as found in this study, are also commonly observed in primiparous mares, since they present a virgin endometrium. It is suggested that at least one gestation is necessary for proper development of microcotyledons, and that the decrease in the microcotyledonary area in primiparous mares may result in foals with reduced birth weight [33].

This report showed that the wry nose mare gave birth to a viable foal at 324 days of gestation. The mare presented a healthy pregnancy, with mild changes in the blood gas analysis at foaling, which were compensated at $24 \mathrm{~h}$ postpartum. Similarly, despite the foal showing signs of immaturity and respiratory acidosis at birth, these changes were compensated in the later assessments.

\section{MANUFACTURERS \\ ${ }^{1}$ Cuattro. Golden, CO, USA. \\ ${ }^{2}$ Abbott. Princeton, NJ, USA. \\ ${ }^{3}$ Roche Sistemas de Diagnósticos Ltda. Amadora, Portugal. \\ ${ }^{4}$ Olympus America. Center Valley, PA, USA. \\ ${ }^{5}$ National Institutes of Health. Bethesda, MD, USA.}

Acknowledgments. Our thanks to Ruth Patten for the English spelling check.

Declaration of interest. The authors have no competing interests.

\section{REFERENCES}

1 ABCCC.2017. Regulamento do registro genealógico da raça equina Crioula. Available in: $<$ http://www.cavalocrioulo. org.br/admin/assets/upload/regulamentos/7058986020.pdf>. [Accessed online in January 2018]

2 Abd-EInaeim M.M.M., Leiser R., Wilsher S. \& Allen W.R. 2006. Structural and Haemovascular Aspects of Placental Growth Throughout Gestation in Young and Aged Mares. Placenta. 27(11-12): 1103-1113.

3 Bianco C., Pirrone A., Boldini S., Sarli G. \& Castagnetti C. 2014. Histomorphometric parameters and fractal complexity of the equine placenta from healthy and sick foals. Theriogenology. 82(8): 1106-1112.

4 Bucca S. 2014. How to Assess the Equine Pregnancy by Ultrasonography. AAEP Proceedings. 60: 282-288.

5 Bucca S., Fogarty U., Collins A. \& Small V. 2005. Assessment of feto-placental well-being in the mare from midgestation to term: Transrectal and transabdominal ultrasonographic features. Theriogenology. 64(3): 542-557.

6 Castagnetti C., Pirrone A.J. \& Mari M.G. 2007. Venous blood lactate evaluation in equine neonatal intensive care. Theriogenology. 73(3): 343-357.

7 Cheung C.Y. 1997. Vascular endothelial growth factor: possible role in fetal development and placental function. Journal Society for Gynecology Investigation. 4(4): 169-177.

8 Comline R.S. \& Silver M. 1974. A comparative study of blood gas tensions, oxygen affinity and red cell 2,3 DPG concentrations in foetal and maternal blood in the mare, cow and sow. Journal of Physiology. 242(3): 805-826.

9 Fowden A.L., Giussani D.A. \& Forhead A.J. 2006. Intrauterine Programming of Physiological Systems: Causes and Consequences. Physiology. 21: 29-37.

10 Gaughan E.M. \& Debowes R.M. 1993. Congenital Diseases of the Equine Head. Veterinary Clinics of North America: Equine Practice. 9(1): 93-110.

11 Gayle J.M., Cohen N.D. \& Chaffin M.K. 1998. Factors Associated with Survival in Septicemic Foals: 65 Cases (1988-1995). Journal of Veterinary Internal Medicine. 12(3): 140-146.

12 Hartwig F.P., Antunez Z.L., Santos R.S., Lisboa F.P., Pfeifer L.F.M., Nogueira C.E.W. \& Curcio B.R. 2013. Determining the Gestational Age of Crioulo Mares Based on a Fetal Ocular Measure. Journal of Equine Veterinary Science. 33(7): 557-560.

13 Henneke D.R., Poiter G.D., Kreider J.L. \& Yeates B.F. 1983. Relationship between condition score, physical measurements and body fat percentage in mares. Equine Veterinary Journal. 15(4): 371-372.

14 Koterba A.M., Drummond W.H. \& Kosch P.C. 1990. Equine clinical neonatology. Philadelphia: Lea \& Febiger, $846 \mathrm{p}$.

15 Lester G.D. 2005. Maturity of the neonatal foal. Veterinary Clinics of North America: Equine Practice. 21(2): 333-355.

16 Macdonald A.A., Chavatte P. \& Fownden A.L. 2000. Scanning electron microscopy of the microcotyledonary placenta of the horse (Equus caballus) in the latter half of gestation. Placenta. 21(5-6): 565-574. 
17 Mazzan M.R. 2006. Noninfectious Respiratory Problems. In: Paradis M.R. (Ed). Equine Neonatal Medicine: A casebased approach. Philadelphia: Saunders Elsevier, pp.135-148.

18 Moraes B.S.S., Amaral L.A., Finger I.S., Mazzini A.R.A., Pazinato F.M., Curcio B.R. \& Nogueira C.E.W. 2017. Curva de crescimento em potros da raça crioula do nascimento aos 24 meses de idade. Acta Scientiae Veterinariae. 45: 1474.

19 Pazinato F.M., Curcio B.R., Fernandes C.G., Santos, C.A., Feijó L.S., Varela A.S.J. \& Nogueira C.E.W. 2017. Histomorphometry of the placental vasculature and microcotyledons in Thoroughbred mares with chronic laminitis. Theriogenology. 91: 77-81.

20 Puchol J.L., Herrán R., Durall I., López J. \& Díaz-Bertrana C. 2004. Use of distraction osteogenesis for the correction of deviated nasal septum and premaxilla in a horse. Journal of the American Veterinary Medical Association. 224(7): 1147-1150.

21 Reef V.B., Vaala W.E., Worth L.T., Sertich P.L. \& Spencer P.A. 1996. Ultrasonographic assessment of fetal wellbeing during late gestation: development of an equine biophysical profile. Equine veterinary Journal. 28(3): 200-208.

22 Renaudin C.D., Troedsson M.H.T., Gillis C.L., King V.L. \& Bodena A.1997. Ultrasonographic evaluation of the equine placenta by transrectal and transabdominal approach in the normal pregnant mare. Theriogenology. 47(2): 559-573.

23 Richardson B.S. \& Bocking A.D. 1998. Metabolic and circulatory adaptations to chronic hypoxia in the fetus. Comparative Biochemistry Physiology - Part A: Molecular \& Integrative Physiology. 119(3): 717-723.

24 Satué K., Felipe M., Mota J. \& Muñoz A. 2011. Gestational length in Carthusian broodmares: effects of breeding season, foal gender, age of mare, year of parturition, parity and sire. Polish Journal of Veterinary Sciences. 14(2): 173-180.

25 Schlafer D.H. 2004. Postmortem Examination of the Equine Placenta, Fetus, and Neonate: Methods and Interpretation of Findings. AAEP Proceedings. 50: 144-161.

26 Schumacher J., Brink P., Easley J. \& Pollock P. 2008. Surgical Correction of Wry Nose in Four Horses. Veterinary Surgery. 37(2): 142-148.

27 Schwarzwald C.C., Bonagura J.D. \& Muir W.W. 2009. The cardiovascular system. In: Muir W.W. \& Hubbell J.A.E. (Eds). Equine Anesthesia: Monitoring and Emergency Therapy. 2nd edn. St. Louis: Saunders Elsevier, pp.37-100.

28 Speirs V.C. 1999. Exame Clínico de Equinos. Porto Alegre: Artmed, 366 p.

29 Stoneham S.J. 2006. Assessing the newborn foal. In: Paradis M.R. (Eds). Equine Neonatal Medicine: A case-based approach. Philadelphia: Saunders Elsevier, pp.1-11.

30 Sutaria T.V., Nakhashi H.C., Sutaria P.T., Chauhan P.M., Raval S.H. \& Suthar B.N. 2017. Hydrocephalic fetus with wry nose and its management through fetotomy in a mare. Indian Journal of Animal Reproduction. 38(2): 62-64.

31 Tennent-Brown B. 2014. Blood Lactate Measurement and Interpretation in Critically Ill Equine Adults and Neonates. Veterinary Clinics of North America: Equine Practice. 30(2): 399-413.

32 Wilkins P.A. 2010. Disorders of foals. In: Reed S.M., Bayly W.M. \& Sellon D.C. (Ed). Equine Internal Medicine. 3rd edn. St. Louis: Saunders Elsevier, pp.1513-1528.

33 Wilsher S. \& Allen W.R. 2012. Factors influencing placental development and function in the mare. Equine Veterinary Journal. (41): 113-119. 